\title{
Estilos de ensino para a docência em Educação Física: aspectos históricos e conceituais
}

\author{
Styles of education for teaching in physical education: historical and \\ conceptual aspects
}

\author{
${ }^{1}$ Aline Menezes de Oliveira \\ 2 Juliete Rosana Machado Moreira \\ ${ }^{3}$ Érik Imil Viana Farani \\ ${ }^{4}$ Cláudio Delunardo Severino
}

\author{
1 Graduada em Educação Física \\ 2 Graduada em Educação Física \\ 3 Mestre em Ciências da Saúde e do Meio Ambiente. Docente do Curso de Educação Física - UniFOA \\ 4 Mestre em Ciências da Saúde e do Meio Ambiente. Docente do Curso de Educação Física - UniFOA / claudiodelunardo@gmail.com
}

\section{RESUMO}

O problema central deste trabalho se apresentou durante o nosso processo de formação profissional, por meio da abordagem das diferentes disciplinas no curso de Licenciatura em Educação Física, principalmente pelas experiências absorvidas no estágio, onde pudemos perceber aulas muito semelhantes e deveras repetitivas, nos levando a refletir sobre uma falta de conhecimento teórico por parte dos docentes, no que se refere aos diferentes métodos de ensino. 0 objetivo geral deste trabalho é conhecer, discutir e refletir sobre a importância dos estudos referentes aos métodos de ensino em Educação Física, e, os específicos, conceituar e caracterizar os diferentes estilos de ensino apresentados por Mosston e estudados por diversos autores. Para realização deste estudo, foi empregada a metodologia baseada na pesquisa bibliográfica, expondo os diferentes julgamentos de estudiosos que tratam do tema em questão, especialmente, Faria Junior (1982); Benites e Souza Neto (2006); Gozzi e Ruete (2006); Heine et al. (2009); Krug (2009) e Moura (2009) A metodologia adotada foi a pesquisa bibliográfica, utilizando-se o método descritivo da bibliografia, com abordagem qualitativa.

\section{PALAVRAS-CHAVE:}

Estilos de ensino; conceitos; características.

\begin{abstract}
The central problem of this work was presented during our training process, across the different disciplines in the Bachelor's Degree in Physical Education, mainly absorbed by the experiences on stage, where we realize classes are very similar and repetitive indeed leading us to reflect a lack of knowledge on the part of theoretical teaching in regard to various teaching methods. The overall goal is that this work proposes is to meet, discuss and reflect on the importance of studies on teaching methods in Physical Education, and for specific conceptualize and characterize the different teaching styles presented by Mosston and studied by several authors. For this study, the methodology used was based on literature, exposing the different judgments of scholars dealing with the issue at hand especially, Faria Junior (1982); Benites \& Souza Neto (2006); Ruete \& Gozzi (2006); Heine et al. (2009), Krug (2009) and Moura (2009) The methodology used was the literature research, and used the descriptive method of literature and qualitative approach.
\end{abstract}

\section{KEYWORDS:}

Teaching styles; concepts; characteristics.

\section{Como você deve citar?}

SEVERINO, C. D., et al. Estilos de ensino para a docência em Educação Física: aspectos históricos e conceituais. Cadernos UniFOA, Volta Redonda, n² 25, quadrimestral, p. 113-119, ago. 2014. 


\section{INTRODUÇÃO}

Na matriz curricular do Curso de Licenciatura em Educação Física, faz-se presente o componente curricular obrigatório Estágio Supervisionado em Educação Física escolar, que compreende também a prática de ensino, momento em que ocorre a oportunidade de reflexão sobre diversos aspectos. Dentre eles, a questão que envolve aulas muito semelhantes e repetitivas, apresentando uma possível ausência na diversidade dos estilos de ensino. No sentido de orientar o presente estudo, utilizou-se como referência o Spectrum de Estilos de Ensino, que "se baseia na tomada de decisões, relacionadas com as fases de planejamento, orientação e controle da aprendizagem", este, idealizado por Mosston e descrito no trabalho de Faria Junior (1982) como sendo: Comando, Tarefas, Avaliação Recíproca, Programação Individualizada, Descoberta Orientada e Solução de Problemas.

Torna-se extremamente importante a compreensão de que, devido às inúmeras possibilidades de assuntos a serem desenvolvidos sobre o tema abordado, não se discutirá a metodologia tecnicista de abordagem sistêmica de Singer, Cick e Muska Mosston, que se apresentam no tratamento direto entre embates das diferentes abordagens. Sendo assim, o objetivo geral deste trabalho é conhecer, discutir e refletir sobre a importância dos estudos referentes aos métodos de ensino em Educação Física, e, os específicos, conceituar e caracterizar os diferentes estilos de ensino apresentados por Mosston.

Fazendo uma relação do Spectrum dos estilos de ensino com as ideias de Graça e Mesquita apud Tani, Bento e Petersen (2006), observa-se a importância do planejamento das aulas bem como a preocupação do professor com o desenvolvimento dos alunos. De acordo com os referidos autores, professores dedicados atuam com o propósito de promover a aprendizagem dos alunos e isso envolve planejamento, utilização de materiais adequados, preocupação com o bom andamento das aulas, controle regular dos trabalhos dos alunos, preocupação com alunos que apresentam dificuldades, bom aproveitamento e coerência na utilização de estratégias de ensino. Esses professores assumem com responsabilidade seu papel de facilitador, pois acreditam que todos os alunos podem aprender.

De acordo com o estudo de Graça e Mesquita apud Tani, Bento e Petersen (2006), em um contexto fechado, modelos de instrução diretivos são mais adequados, como no caso dos estilos comando e tarefa. No entanto, eles perdem a vantagem quando se trata de questões relacionadas à criatividade e à descoberta, nas quais estilos como descoberta orientada e solução de problemas seriam mais adequados. Desse modo, observou-se que comportamentos de ensino devem ser traçados de acordo com as circunstâncias concretas em que o professor trabalha, ou seja, não há modelos ou receitas. Cada situação de aprendizagem exige um estilo de ensino diferenciado e cabe ao professor realizar essa análise dando às suas aulas um verdadeiro propósito.

A partir daí, apresenta-se o Spectrum de estilos de ensino idealizado por Mosston, que em outras palavras, trata-se de um quadro comparativo entre os diferentes estilos. Nele, identifica-se a estrutura de cada estilo, analisando as decisões que são tomadas pelo professor e pelo aluno, descrevendo como mudar as decisões do primeiro para o segundo, na medida em que os dois se movimentam de estilo a estilo, além de descrever a influência de cada um nos domínios cognitivo, afetivo, social, físico e moral do aluno (FARIA JUNIOR, 1982; KRUG, 2009).

Para realização deste estudo, foi empregada a metodologia baseada na pesquisa bibliográfica, expondo os diferentes julgamentos de estudiosos que tratam do tema em questão, especialmente, Faria Junior (1982) e Krug (2009). Utiliza-se também, como fonte de pesquisa, artigos de diferentes autores, como Benites e Souza Neto (2006); Gozzi e Ruete (2006); Heine et al. (2009) e Moura (2009), que defendem a diversidade dos Estilos de Ensino como forma de enriquecer as aulas e proporcionar aos alunos vivências e práticas diferenciadas. 


\section{ASPECTOS HISTÓRICOS: MUSKA MOSSTON E OS ESTILOS DE ENSINO}

O Spectrum nasceu na Educação Física e se expandiu tanto nas suas percepções teóricas de ensino, como na sua aplicação prática em outras áreas do currículo. Foi estudado em vários países como, Espanha, Grécia, Finlândia, Estados Unidos, Canadá, Grã-Bretanha e países da América Latina como, Argentina e Brasil, entre outros.

Durante a década de 1960, mais precisamente a partir de 1965, o professor Mosston demonstra uma preocupação com as formas de comunicação utilizadas por diferentes professores de Educação Física, indicando diretamente as interferências entre as atitudes de ensinar e aprender, culminando com a apresentação de seu trabalho sobre estilos de ensino junto à comunidade científica, no qual a teoria do relacionamento entre professores e alunos se apresenta com grande ênfase, codificada através de uma espécie de diagrama, conhecido como Spectrum dos estilos de ensino.

O Spectrum foi formulado devido à fragmentação existente no ensino, a qual foi evidenciada em dois movimentos de pesquisa proeminentes da época, que são eficácia no ensino, rica em princípios e técnicas e embasada por volumosas pesquisas, que apontavam para a melhoria do desempenho na sala de aula (BERLINER 1976, 1984; JOYCE 1980 apud KRUG, 2009); e habilidades de pensamento, rica em análise do processo de pensamento, modelos de comportamento cognitivo, meta-cognição, pensamento crítico, criatividade, solução de problemas, análise de tarefas, questionamento e programas para o ensino do pensamento (OXMAN, 1984 e 1985 apud KRUG, 2009).

As escolas públicas vizinhas à Rutgers University, nos Estados Unidos, foram as primeiras a utilizarem o Spectrum, fazendo com que todos os professores participassem da experimentação, podendo assim, identificar problemas e resolvê-los da melhor forma possível. Para o autor (op cit.), o Spectrum é ensinável e pode ser aprendido por qualquer professor que esteja disposto a ir ao encontro das necessidades de seus alunos e ajudá-los a desenvolver suas potencialidades.

\section{OS ESTILOS DE ENSINO E SEU VALOR PARA PRÁTICA DOCENTE}

De acordo com Darido (2003), no fim da década de 1970, estudiosos da Educação Física escolar iniciaram alguns movimentos em oposição ao tecnicismo, esportivismo e à visão biologicista que se dava à área. Por meio desses esforços que buscavam afastar a Educação Física escolar do modelo tecnicista, esses movimentos culminaram com as concepções que se apresentam hoje como: Desenvolvimentista, Construtivista-interacionista, Crítico-superadora, Sistêmica, Psico-motricista, Crítico-emancipatória, Cultural, as apoiadas nos Jogos Cooperativos, no modelo de Saúde Renovada e à relacionada aos Parâmetros Curriculares Nacionais.

Observa-se que vários estudiosos desenvolveram suas teorias sobre abordagens, conteúdos, métodos, enfım, muito foi discutido e produzido em prol do avanço dessa disciplina. Segundo Benites e Souza Neto (2006), existem inúmeras formas de se pensar a Educação Física, devido à enorme gama de informações existentes, nos dando a impressão de não haver limites para a pesquisa nesse campo.

Para Heine et al. (2009), uma variedade de estratégias de ensino pode ser utilizada para desenvolver um determinado conteúdo. Cada estratégia tem suas vantagens e desvantagens, dependendo da situação específica da aula, conteúdo, objetivo e do processo de ensino desejado. Um critério importante na seleção da estratégia é conhecer o processo, suas características inerentes e implicações para o desenvolvimento da criança. Essa afirmação vem ratificar a complexidade existente entre o processo de ensino-estudo-aprendizagem, justificando assim a busca evidente de diferentes pesquisadores. 
Dentre as teorias sobre maneiras de ensinar Educação Física escolar, encontra-se o Spectrum dos estilos de ensino, que ajuda no relacionamento entre professor e aluno, fazendo com que a aula desenvolva a troca de ideias e a flexibilidade, o que permite ao educador trazer para seu planejamento novas perspectivas, tornando-o observador, criador e conselheiro, de forma a impulsionar o aluno a avançar em sua independência (GOZZI e RUETE, 2006).

O Spectrum "é uma classificação construída para a Educação Física e apresenta características do não versus, ou seja, nenhum estilo de ensino, por si só, é melhor ou pior que outro" (MOURA, 2009, p. 01). Logo, a escolha do professor em relação a que estilo utilizar, está diretamente relacionada à atitude do aluno e sua maneira de aprender. Para Gozzi e Ruete (2006), reconhecendo as características de cada estilo, o professor tem à sua disposição um leque de possibilidades, o que é importante devido às diferenças existentes entre seus alunos seja em comportamento, nível de aprendizado, etc.

Mosston e Ashworth (1994 apud HEINE, 2009) citam três razões para desenvolver a variedade de estilos de ensino. A primeira refere-se à forma preferida de ensinar, baseada em valores individuais e nas experiências pessoais. A segunda razão refere-se à individualidade. Os alunos aprendem de maneiras diferentes, assim como possuem formação cultural e experiências de movimentos diferentes. A terceira razão, que levou ao desenvolvimento do Spectrum, é que cada um dos estilos de ensino contribuem, em diferentes níveis, para o desenvolvimento das dimensões do ser humano.

De acordo com Garn e Byra (2002 apud HEINE, 2009), o Spectrum de estilos de ensino foi estruturado, considerando-se que os alunos possam reproduzir e produzir movimentos e conhecimento. No caso da Educação Física e de seus conteúdos, todas as atividades têm componentes que podem ser ensinados, utilizando-se estilos de ensino reprodutivos (comando, tarefas, avaliação recíproca, avaliação recíproca e programação individualizada) e produtivos (descoberta orientada e solução de problemas). As decisões tomadas pelo professor (ensino) na escolha dos diferentes estilos de ensino é que vão definir a maneira com que o aluno vai aprender (aprendizagem).

\section{CONCEITOS, CARACTERÍSTICAS E EXEMPLIFICAÇõES DOS DIFERENTES ESTILOS DE ENSINO: EM BUSCA DE UM MELHOR ENTENDIMENTO}

No que tange à atualidade do Spectrum, faz-se necessário lembrar as palavras de Saviani apud SOARES et al., 1992), quando expõe sobre o trato com o conhecimento. $O$ autor observa que o conteúdo clássico não perde sua contemporaneidade, já que não se confunde com o tradicional e também não se opõe ao moderno e ao atual. Dessa forma, vê-se que os estilos de ensino fazem parte de um arsenal de ferramentas a serem utilizadas a favor do ensino, mais especificamente, do ensino da EF escolar.

Os diferentes estilos de ensino criados por Mosston e citados nos trabalhos de Faria Junior (1982) e Krug (2009) são:

Comando - A essência desse estilo é uma relação professor-aluno-objetivo, buscando produzir uma série de resultados (FARIA JUNIOR, 1982; KRUG, 2009). O professor toma todas as decisões e 0 aluno as segue de modo que, dessa forma, os objetivos são alcançados. A essência desse estilo é um relacionamento direto entre o estímulo do professor e a resposta do aluno.

Tarefa - Nesse estilo, o papel do professor é tomar todas as decisões nas fases pré e pós-impacto para, na fase de impacto, oferecer ao aluno algumas oportunidades de tomar decisões. 0 papel do aluno 
é executar a tarefa demonstrada pelo professor e tomar as decisões possíveis dentre as que lhe foram passadas. No Spectrum, esse estilo, apesar de ainda ter o professor como centro do processo, representa um primeiro passo em direção ao ensino centrado no aluno (FARIA JUNIOR, 1982; KRUG, 2009).

Observa-se que, nesse estilo, há um indício de preocupação com o conhecimento do aluno, ou seja, ele começa a exercer um papel menos submisso e mais participativo, o que a nosso ver é importante, pois o aluno percebe que o professor confia nele e isso o encoraja a agir por si só, tomando iniciativa e assim adquirindo confiança em si mesmo. Ressalta-se a atenção do professor no sentido de não transformar esse estilo em Comando, já que suas características são semelhantes.

Avaliação recíproca - Esse estilo é um segundo passo na direção de tornar o aluno independente, ou seja, o professor ainda tem um papel superior no processo, mas ele oferece aos alunos a avaliação da aprendizagem, ou seja, o professor toma todas as decisões na fase de pré-impacto, o executante efetua as ações desejáveis na fase de impacto e há um aluno observador que atua na fase pós-impacto (FARIA JUNIOR, 1982; KRUG, 2009).

Percebe-se que, nesse estilo, os alunos reconhecem os pontos positivos e negativos de seu desempenho nas atividades por meio dos colegas, o que é muito interessante, pois alimenta a relação de confiança entre os alunos, além de permitir que eles identifiquem possíveis falhas em seu próprio rendimento. Um aluno ajuda o outro a identificar seus pontos fracos e, juntos, buscam maneiras de melhorar seu desempenho nas atividades. Pontua-se a ênfase na construção cognitiva, pois acredita-se ser uma das características mais latentes desse estilo, observar, detectar e intervir na forma de execução, levando à aprendizagem do avaliador e do avaliado.

Programação individualizada - Trata-se de um estilo desenvolvido no sentido de libertar o aluno do seu estado de dependência (FARIA JUNIOR, 1982; KRUG, 2009). Baseia-se no princípio da individualidade, respeitando as diferenças entre os alunos, de forma que cada um trabalhe em seu ritmo, desenvolvendo o senso de responsabilidade e iniciativa. 0 papel do professor é de grande importância no preparo dos programas e sua maior preocupação é com a aprendizagem dos alunos. Nesse estilo, o professor apresenta o conteúdo sob a forma de programas individualizados, no qual cada aluno recebe uma ficha com as atividades a serem desenvolvidas e eles mesmos fazem a avaliação de seu desempenho. Entende-se que o estilo programação individualizada é extremamente benéfico para o aluno, porque ele consegue identificar suas próprias limitações e/ou avanços, mas é um estilo de difícil execução, já que o professor precisa organizar atividades diferentes para cada aluno e também acompanhar cada um no desenvolvimento das mesmas. Observa-se, também, que é difícil para o professor avaliar, em uma turma numerosa, a maturidade dos alunos, no sentido de possuírem ou não capacidade de analisar seu próprio desempenho, visto que a maturidade do aluno é condição preponderante para a experimentação do estilo em questão.

Descoberta orientada - Nesse estilo uma sequência de questões propostas pelo professor desencadeia uma sequência correspondente de respostas do aluno. No entanto, cada questão levantada deve provocar uma única resposta correta. Caso isso não aconteça, o professor deve buscar outras questões que conduzirão o aluno à resposta que se pretende alcançar (FARIA JUNIOR, 1982; KRUG, 2009). Na fase pré-impacto, quem toma as decisões é o professor: na fase de impacto, mais decisões são passadas para o aluno e, na fase pós-impacto, o professor verifica as respostas dos mesmos. Em alguns casos, os próprios alunos conseguem verificar as respostas. Nesse estilo, o professor começa a assumir o papel de incentivador e orientador, auxiliando e esclarecendo os alunos.

Acredita-se que esse estilo proporciona aos alunos a possibilidade de desenvolver o raciocínio, 0 pensamento, o que fazer como fazer e não apenas fazer. Esses questionamentos conduzem o aluno a 
um processo de autonomia, pois ele começa a utilizar os conhecimentos adquiridos na construção de novos conhecimentos, respondendo às perguntas do professor, geralmente ligadas ao domínio cognitivo.

Solução de problemas - Esse estilo ocupa a posição de maior destaque no Spectrum (FARIA JUNIOR, 1982), pois causa mudanças fundamentais no papel do professor, delegando-o maiores responsabilidades. Ele passa a ser incentivador e orientador do aluno, desempenhando um papel de conselheiro. 0 aluno é colocado no centro do processo educativo, passando a ser elemento ativo, aprendendo com as resoluções de problemas reais e significativos, de forma a tomar decisões, indo além do que é conhecido. Um problema é composto por situações ricas e requer do aluno a percepção para escolher, entre várias soluções, a que lhe pareça mais apropriada. Dessa forma, a preocupação não é apenas com a solução do problema, mas também, e, principalmente, com a busca de uma forma mais eficaz de solucioná-lo, o que leva o aluno a um processo de autoaperfeiçoamento.

Diante das informações, acredita-se que a solução de problemas é um estilo apropriado, quando o objetivo do professor é promover em seus alunos um estado de cidadania crítica e responsável por suas escolhas. Apesar disso, há a consciência da dificuldade na aplicação desse estilo, pois envolve muita dedicação e comprometimento por parte do professor, no que se refere ao tempo disponível, à colaboração por parte da escola (coordenação, direção, etc) e à aceitação dos próprios alunos que, em sua maioria, não gostam ou não se sentem motivados a experimentar o novo por conta do processo de alienação a que vem sendo submetidos há tempos. Entretanto, observa-se uma diferença básica entre o estilo em questão e o anterior, que é a falta de controle do professor em relação às respostas encontradas pelos alunos na solução dos problemas.

\section{CONSIDERAÇÕES FINAIS}

Não podemos negar que a investigação do conhecimento por parte dos profissionais da educação é essencial para o sucesso do processo ensino-estudo-aprendizagem. A notoriedade da necessidade de utilização dos distintos métodos à disposição da área da Educação Física gera a necessidade premente do estreitamento entre o docente e os diferentes estudos teóricos existentes, buscando o entendimento imediato de sua prática laboral.

Advertimos, anteriormente, que os métodos apresentados neste estudo são referentes às aplicações de ordem prática, portanto faz-se necessário o surgimento de distintos estudos que possam adequá-los aos das diferentes correntes e tendências. Observa-se que essa advertência não se refere unicamente aos métodos característicos da Educação Física, mas também aos que possam ser adaptados à área em determinadas situações ou utilizados em momentos estratégicos, perspectivando o enriquecimento das nossas práticas pedagógicas.

Acreditamos que o estudo apresentado por Mosston, discutido por Faria Junior (1986) e Krug (2009), não se apresenta como único, mas, conforme visto no decorrer da presente pesquisa, pode-se apontá-lo como importante ferramenta de trabalho para toda comunidade da área.

Finalizamos com a certeza de que este tema ainda terá vários desdobramentos, com possibilidades de novas pesquisas, como também com o intuito de sensibilizar os leitores para a necessidade do entendimento conceitual dos métodos, pois esse é um importante passo para iniciarmos uma necessária reflexão e, quem sabe, perspectivar um espaço para discussão, no que tange ao estudo dos métodos na área da Educação Física. 


\section{REFERÊNCIAS}

BENITES, L. S.; SOUZA NETO, S.. Os saberes docentes e a prática pedagógica nas tendências de ensino da educação física. 2006. Disponível em: <http//www.efdeportes.com>. Acesso em: 18 fev. 2012.

CRUZ, C; RIBEIRO, U. Metodologia científica: teoria e prática. 2. ed. Rio de Janeiro: Axcel Books do Brasil, 2004.

DARIDO, S. C. Educação física na escola: questões e reflexões. Rio de Janeiro, RJ: Guanabara Koogan, 2003.

FARIA JUNIOR, A. G. Prática de ensino em educação física: estágio supervisionado. Rio de Janeiro: Guanabara, 1982.

GOZZI, M. C. T.; RUETE, H. M. Identificando estilos de ensino em aulas de educação física em segmentos não escolares. 2005. Artigo. - Revista Mackenzie de Educação Física e Esporte, ano 5. n. I, 2006.

KRUG, D. F. Metodologia do ensino: educação física. Curitiba: JM Livraria Jurídica, 2009.

MOURA, D. L. A Educação física escolar e os estilos de ensino: uma análise de duas escolas do Rio de Janeiro. 2009. Disponível em: <http//www.efdeportes.com/>. Acesso em 18 fev. 2012.

SANTOS, A. R. Metodologia científica: a construção do conhecimento. 7. ed. Rio de Janeiro: DP\&A, 2001. SOARES, C. L. et al. Metodologia do ensino de educação física. São Paulo: Cortez, 1992.

TANI, G; BENTO, J. O.; PETERSEN, R. D. S. Pedagogia do desporto. Rio de Janeiro: Guanabara Koogan, 2006. 